\title{
PROCESSOS EDUCATIVOS E CANAIS DE COMUNICAÇÃO ${ }^{1}$
}

\section{Paradigma informacional impede o diálogo, base da apropriação do conhecimento, transformando educação a distância em (in)comunicação}

Isso que vês, como expressarás com palavras? O mundo nos entra pelos

olhos porém não adquire sentido até que desça à nossa boca.

Paul Auster

Convém começar situando o ponto de vista a partir do qual apresentaremos estas reflexões. Em sua prática, na definição de seus objetivos, na determinação de suas aplicações e suas relações, a Comunicação Educativa vem tendendo pronunciadamente a limitar seu âmbito à mídia; a estabelecer uma implícita equivalência em virtude da qual, quando enuncia Comunicação, automaticamente se refere a meios e tecnologias de comunicação.

Cremos que é fundamental ultrapassar esta visão redutora e postular que a Comunicação Educativa abarca certamente o campo da mídia, mas não apenas esta área: abarca também, e em lugar privilegiado, o tipo de comunicação presente em todo processo educativo, seja ele realizado com ou sem o emprego de meios. Isso implica considerar a Comunicação não como um mero instrumento midiático e tecnológico, e sim, antes de tudo, como um componente pedagógico. Enquanto interdisciplina e campo de conhe- cimento, para a Comunicação Educativa, entendida desse modo, convergem uma leitura da Pedagogia a partir da Comunicação e uma leitura da Comunicação a partir da Pedagogia.

Ao conceber essa dimensão ampla, chama-se a atenção para o fato de que ela enfrenta nesta hora uma encruzilhada na qual se jogam seu destino e sua conformação futura. Se o paradigma informacional atualmente no auge acaba por dominar, não restará à Comunicação Educativa presumivelmente outra função que a instrumental: a de prover de recursos didáticos e tecnológicos um modelo de educação cujas coordenadas pedagógicas estarão sendo determinadas sem sua participação.

Para caracterizar este paradigma que aparece como hegemônico, parece-nos bem representativa uma passagem de um artigo publicado recentemente em uma renomada revista latino-americana de Comunicação. Ao expor as potencialidades da informática

\section{O AUTOR}

\section{Mário Kaplún*}

Especialista em Comunicação e consultor independente no Uruguai. Membro do Conselho de Colaboradores Internacionais de Comunicação \& Educação.

1. Este artigo, sob o título de Procesos educativos y canales de comunicación, foi originalmente apresentado no I Congresso Internacional de Comunicação e Educação - Multimídia e Educação em um Mundo Globalizado -, em maio de 1998, São Paulo, Brasil, e organizado pelo Núcleo de Comunicação e Educação, CCA-ECA-USP e pelo WCME - World Council for Media Education.

* Faleceu a 10 de novembro de 1998 . Veja nota na página 135 desta edição. 
no desenvolvimento da moderna sociedade do conhecimento, o autor vaticina para um futuro próximo - e o prognóstico parece bastante factível - a implantação da "educação a distância por meios eletrônicos", isto é, "a possibilidade, tecnologicamente certa, da criação de aulas virtuais", nas quais cada estudante em sua própria casa poderá dispor de "toda a informação necessária. A rede informática, o CD-Rom, a Internet e os novos softwares, constituídos em ferramentas de aprendizagem, lhe abrirão horizontes inusitados para suas tarefas educativas. $\mathrm{O}$ disco compacto, capaz de concentrar uma imensa quantidade de informação em forma de texto, imagem, gráficos e som, permitirá ao estudante 'navegar' por suas informações". Por sua vez, "a Internet lhe proporcionará conhecimentos atuais sobre todos os temas imagináveis e lhe abrirá possibilidades infinitas de dados colaterais acerca deles"2.

\section{EDUCAÇÃO E PARADIGMAS}

Se partimos de um olhar fundamentado no ponto de vista tecnológico, não há dúvida de que a conformação deste ciberespaço educativo implica um espetacular avanço. Mas, a partir de uma racionalidade pedagógica, não representará também, por outro lado, um estancamento e inclusive, talvez, uma involução? Não estamos ante a velha "educação bancária" tantas vezes condenada por Paulo Freire 3 , só que agora em sua moderna versão de caixa automático dos ban$\cos$ ? Essa desejada aula virtual não é senão o ápice previsível de uma matriz que já estava se instaurando e vitalizando-se faz bastante tempo, e que se identifica como um de seus traços mais salientes, por seu caráter individualizado, isto é, por estar dirigida a indivíduos isolados, considerados como mônadas unitárias (em sentido figurado, aqueles indivíduos que vagam perdidos de seu grupo social), receptoras de instrução.

O ensino atual em todos os níveis desde a escola primária até o terceiro grau está marcado por esta matriz. Até recentemente, o caráter social e comunitário da educação era não só considerado como uma condição natural, inerente à mesma, mas também como um valor. A escola existia por uma razão pragmática - a necessidade de atender simultaneamente a uma quantidade de educandos em um mesmo espaço físico mas, e não em menor medida, por uma razão pedagógica: como espaço gerador da socialização e possibilitador das interações grupais, valorizadas como um componente básico e imprescindível dos processos educativos. Recordem-se as propostas de Dewey ${ }^{4}$ e sua valorização do trabalho em equipe; os aportes metodológicos de Freinet $^{5}$, centrados no intercâmbio de jornais escolares produzidos e comunicados entre os alunos, organizados em redes de interlocução, como marco propício para o desenvolvimento da auto-expressão dos escolares; o construtivismo sociointeracionista de Vygotsky e Bruner, para quem a aprendizagem é sempre um produto social. "Aprendemos dos outros e com os outros", sustentará Vygotsky: "No desenvolvimento [do educando] toda função aparece duas vezes: primeiro em nível social e mais tarde em nível

2. BORJA, R. La democracia del futuro (A democracia do futuro). Chasqui. Quito, n. 56, dic. 1996.

3. FREIRE, P. Pedagogia do oprimido. 6. ed. Rio de Janeiro: Paz e Terra, 1978. (N. Ed.)

4. DEWEY, J. Democracia e educação. São Paulo: Nacional, 1952. PITOMBO, M. I. Conhecimento, valor e educação em John Dewey. São Paulo: Pioneira, 1974. (N. Ed.)

5. Para saber mais sobre o autor ver: FREINET, C. Método natural. Lisboa: Estampa, 1977. derna. 4. ed. Lisboa: Estampa, 1975. Jornal escolar. Lisboa: Estampa, 1974. (N. Ed.) Técnicas da escola mo- 
individual; primeiro entre pessoas (intersubjetiva) e depois no interior do próprio educando (intra-subjetiva). Todas as funções superiores da inteligência - seja a atenção voluntária, a memória lógica, a formação de conceitos - originam-se como relações entre os seres humanos"6. A isso Bruner acrescentará que, se a reflexão é indubitavelmente uma fase vital em todo autêntico processo de aprendizagem, ela "é muito mais fácil de iniciar em companhia que em solidão. $\mathrm{O}$ pensamento começa sendo um diálogo que depois se $f a z$ interior" 7 . E eram tanto sociopolíticos quanto pedagógicos os fundamentos que levaram Paulo Freire a postular que "o grupo é a célula educativa básica" 8 . Mas este paradigma já não parece predominar. Foi perdendo valor, peso, importância.

À medida que o ensino foi se massificando, foi restando cada vez menos espaço para a comunicação e os intercâmbios entre os educandos. Mas não só menos espaço: também menos interesse e menos vontade para propiciá-lo, menos consciência do alcance do diálogo como componente necessário da ação educativa. Dissimuladamente, sem apregoá-lo, foi sendo deslocado e substituído pelo paradigma informacional.

O deslocamento foi impulsionado pelo desenvolvimento da modalidade que hoje se encontra em mais rápida expansão em todo o mundo: o ensino a distância ${ }^{9}$. Com o crescimento dessa modalidade, a opção que já tomava conta de fato do ensino presencial instaura-se de pleno direito: para o modelo hegemônico de educação a distância, a individuação passa a ser um pressuposto intrínseco. "O ensino a distância serve expressamente ao estudante individual, no estudo que este realiza por si mesmo" 10 , um de seus traços definidores é "o ensino aos estudantes como indivíduos e raramente em grupos" 11 , já que "as oportunidades ocasionais de encontros com seus supervisores, com os professores e com outros estudantes" constituem "um recurso caro" e que "não está previsto" 12 . Tais encontros podem dar-se circunstancialmente, mas não são reconhecidos, de modo algum, como condição específica do sistema.

Devido ao emprego intenso de meios, costuma vincular-se esta modalidade de ensino à comunicação. Mas quando os especialistas explicitam os fluxos comunicacionais do sistema, costumam defini-los em termos de bidirecionalidade, entendendo-a exclusivamente como "uma comunicação organizada de ida e volta entre o estudante e a organização de apoio"'13, isto é, como a existência de "meios de contato entre o estudante e seu supervisor", também chamado tutor ${ }^{14}$. Outros autores relativizam inclusive a real dimensão desse componente. Assim, por

6. VYGOTSKY, L. El desarollo de los pocesos psicológicos superiores ( $\mathrm{O}$ desenvolvimento dos processos psicológicos superiores). Barcelona: Crítica, 1978.

7. BRUNER, J. Acción, pensamiento y lenguaje (Ação, pensamento e linguagem). Barcelona: Alianza, 1984.

8. FREIRE, P. Pedagogia do oprimido. op, cit.

9. CAVANAGH, C. H. El aprendizaje de los adultos, los medios de comunicación, la cultura y las nuevas tecnologias de la informacion y la comunicación (O aprendizado dos adultos, os meios de comunicação, a cultura e as novas tecnologias de informação e de comunicação). Educación de adultos y desarollo (Educação de adultos e desenvolvimento). Bonn, n. 49 , 1997. KAYE, A. La enseñanza a distancia: situación actual (O ensino a distância: situação atual). Perspectivas. Paris: Unesco, n. $65,1988$.

10. HOLMBERG, B. Educación a distancia: situación y perspectivas (Educação a distância: situação e perspectivas). Buenos Aires: Kapelusz,1985.

11. KEEGAN, D. The foundation of distance education (As bases da educação a distância). London: Croom Helm, 1986.

12. KAYE, A. La enseñanza a distancia... op. cit.

13. HOLMBERG, B. Educación a distancia... op. cit.

14. KAYE, A. La enseñanza a distancia... op. cit. 
exemplo, Rowntree ${ }^{15}$ afirma que o estudo se realiza basicamente por meio dos materiais didáticos previamente preparados, enquanto "o contato direto com os professores é escasso". Sarramona coincide em reconhecer a inviabilidade de estabelecer, na modalidade a distância, esta comunicação bidirecional docente/discente de forma fluida e freqüente. Mas, ainda que assim não fosse, o que importa sublinhar é que, no melhor dos casos, o educando conta com um único interlocutor; e isso só para fazer-lhe perguntas e despejar dúvidas sobre aspectos que não estão suficientemente claros nos textos de estudo.

Não é de surpreender, então, que, com a revolução tecnológica, esse processo ascendente de individualização e de fortalecimento do paradigma da informação venha a culminar nessa "sala de aula virtual", na qual um educando isolado, em total solidão, poderá abrir as comportas a um volume torrencial de informação, o que supostamente o habilitará a apropriar-se do conhecimento. Mesmo esse mínimo contato com um supervisor ou tutor, que alguns metodólogos tentaram preservar no ensino a distância, é eliminado, para ser substituído por bases de dados informatizadas.

Levando-se em consideração que, ao dar ênfase a determinadas práticas e desestimular e excluir outras, todo sistema de ensino supõe um currículo oculto ${ }^{16}$, indaguemos em que reside o encoberto, o não dito, neste projeto de educação informatizada. Temos que considerar não só o que ele propõe mas também o que caladamente torna supérfluo e mesmo subtrai ao estudante: o grupo e a palavra. A "sala de aula virtual" institui um educando que estuda sem ver ninguém, sem falar com ninguém: privado de interlocutores, fica confinado a um perene silêncio.

\section{(IN)COMUNICAÇÃO NA EDUCAÇÃO Á DISTÂNCIA}

Há duas perguntas para as quais a educação a distância, em seu modelo hegemônico, não só não dá resposta, como também sequer as formula. Uma, com quem se comunica - tomando o verbo comunicar-se em sua real dimensão - este navegante solitário do conhecimento? (O único que responde honestamente a essa pergunta é Sarramona, o qual reconhece que na educação a distância o estudante "só se comunica e dialoga consigo mesmo"). A outra, que canais o sistema coloca à disposição para que o estudante exercite sua própria expressão? Isto é, que espaço the é oferecido para ser ele, por sua vez, lido e escutado, para dialogar com seus companheiros de navegação, enriquecer-se com suas contribuições e compartilhar e confrontar seu próprio pensamento? Perguntas que, por sua vez, suscitam outras: a comunicação só consiste em poder fazer consultas e aclarar dúvidas?; o estudante não tem nada propriamente valioso para dizer?; a única comunicação que importa preservar é a do aluno com o docente?; a comunicação dos estudantes entre si não é um componente capital no processo da aprendizagem?

Assim, esta era da hipercomunicação e do ciberespaço, do teletrabalho e da sala de aula virtual dá lugar justificadamente a um duplo movimento, de entusiasmo e de desconfiança. O que estamos presenciando nesse setor não parece encaminhar-se para a concretização dessa aldeia global do sonho mcluhaniano e sim para a instauração de um arquipélago global, composto de seres tecnologicamente hipercomunicados mas socialmente isolados (veja-se a tão elogiada

15. Apud: GARCIA ARETIO, L. Un concepto integrador de educación a distancia (Um conceito integrador de educação a distância). Palestra apresentada na XV Conferência Mundial de Educação a Distância. Caracas, nov. 1990.

16. JACKSON, P. Life and classrooms (Vida e sala de aula). New York: Holt, Rinehart \& Winston, 1968. APPLE, M. Ideologia y currículo (Ideologia e currículo). Madrid: Akal, 1986. Educación y poder (Educação e poder). Barcelona: Paidós, 1987. 
interatividade, plena de ambigüidade: no mais das vezes, refere-se à ida e volta que se estabelece entre o ser humano e a máquina e não entre pessoas). $\mathrm{O}$ que seus profetas omitem perguntar-se é o que poderão intercambiar e comunicar-se pessoas que vivam isoladas as 24 horas do dia. Tecnologicamente, terão mais possibilidades que nunca de interconectar-se; mas, esgotado o interesse pelos outros, extinta a prática da participação social e cidadã, lhes restará para comunicar algo além do intercâmbio de pseudo-experiências virtuais?

Os saldos sociais e políticos dessa educação individualizada aparecem suficientemente evidentes: de estudantes educados em e para o silêncio cabe esperar cidadãos passivos e não participantes ${ }^{17}$. Talvez sejam menos percebidos, em contrapartida, os que concernem ao campo pedagógico.

Vamos nos limitar a assinalar dois, por estarem ambos particularmente vinculados ao campo da Comunicação Educativa.

Em todas as modernas teorias da aprendizagem, a linguagem desempenha uma função imprescindível: uma aprendizagem que leve à compreensão culmina com a aquisição e incorporação, por parte do educando, dos símbolos linguísticos representativos dos conceitos adquiridos. Como o sugere a frase de Auster na epígrafe destas notas, o conceito pode existir porque existem as palavras que o representam.

Em uma passagem de seu livro Pensamento e linguagem, Vygotsky cita uns versos do poeta russo Mandelstam: "Esqueci as palavras que queria pronunciar e meu pensamento, incorpóreo, regressa ao reino das sombras". E comenta: "A relação entre pensamento e palavra é um processo vivente: o pensamento vive através das palavras. Uma palavra sem pensamento é uma coisa morta e um pensamento desprovido de palavras permanece na sombra". As indagações psicogenéticas de Vygotsky revelaram o papel capital da linguagem no desenvolvimento das faculdades cognitivas: "O desenvolvimento do pensamento está determinado pela linguagem (....) $\mathrm{O}$ desenvolvimento da lógica é uma função direta da linguagem socializada (....) O crescimento intelectual depende do domínio dos mediadores sociais do pensamento, isto é, do domínio das palavras. A linguagem é a ferramenta do pensamento" 18 .

Então, vejamos: como o sujeito educando adquire sua competência lingüística, isto é, o domínio e a apropriação dessa ferramenta indispensável para construir o pensamento e conceitualizar suas aprendizagens? A resposta se encontra novamente no pesquisador russo, quando assevera que "as categorias de estruturação do pensamento procedem do discurso e do intercâmbio", mediante os quais o ser humano se apropria desses símbolos culturalmente elaborados as palavras - que lhe permitem, por sua vez, comunicar-se e representar os objetos, quer dizer, pensar. A essa mesma dupla função da linguagem alude Bruner, quando ressalta sua natureza bifrontal: "é um meio de comunicação e por sua vez a forma de representar o mundo acerca do qual nos comunicamos. Não só transmite, mas também cria e constitui o conhecimento" 19 .

A linguagem, matéria-prima para a construção do pensamento e instrumento essencial do desenvolvimento intelectual, adquire-se, pois, na comunicação, nesse cons-

17. MARQUES DE MELO, J. Derecho a la información: agenda para el debate (Direito à informação: agenda para o debate).

Chasqui. Quito, n. 59, set.1997.

18. VYGOTSKY, L. Pensamento e linguagem. São Paulo: Martins Fontes, 1987.

19. BRUNER, J. Acción, pensamiento... op. cit. 
tante intercâmbio entre as pessoas que torna possível exercitar o pensamento e, desse modo, apropriar-se dele. Não basta receber (ler ou ouvir) uma palavra para incorporá-la ao repertório pessoal; para que ocorra sua efetiva apropriação é preciso que o sujeito a use e a exercite, que a pronuncie, escreva, aplique. Esse exercício só pode dar-se na comunicação com outros sujeitos, escutando e lendo outros, falando e escrevendo para outros. Pensamos com palavras; mas a aquisição das palavras é um fato cultural, isto é, um produto do diálogo no espaço social. Esse instrumento imprescindível, que é o acervo lingüístico, só se internaliza e se amplia na constante prática da interlocução.

Para cumprir seus objetivos, todo processo de ensino/aprendizagem deve, então, dar lugar à manifestação pessoal dos sujeitos educandos, desenvolver sua competência lingüística, propiciar o exercício social através do qual se apropriarão dessa ferramenta indispensável para sua elaboração conceitual. Em lugar de confiná-los a um mero papel de receptores, é preciso criar as condições para que eles mesmos gerem mensagens próprias, pertinentes ao tema que estão aprendendo.

Do ponto de vista metodológico, há outra consequiência importante desta relação entre aprendizagem e exercício da expressão. $\mathrm{O}$ postulado poderia ser enunciado assim: $\mathrm{o}$ sujeito educando consegue expressar uma idéia de modo que os outros possam compreendê-la, somente quando ele mesmo a compreende e a apreende verdadeiramente ${ }^{20}$.
Comunicar é conhecer. O sentido não é só um problema de compreensão e sim, sobretudo, um problema de expressão $0^{21}$. Chega-se ao pleno conhecimento de um conceito quando surge a oportunidade e, por sua vez, o compromisso de comunicá-lo a outros. Os educadores experimentamos isso permanentemente: compare-se o grau de apropriação de um conhecimento que tínhamos quando, em nosso período de formação, estudávamos para nós mesmos e o incomparavelmente maior que alcançamos quando devemos transmitir essas mesmas noções a nossos alunos de modo claro, organizado e compreensível. A grande quantidade de informação é tão importante para o domínio de um tema quanto a prática de expressá-lo.

O grande narrador peruano Julio Rámon Ribeyro, referindo-se à comunicação escrita resgata experiência similar: "Escrever, mais que transmitir um conhecimento, é ter acesso a esse conhecimento. $\mathrm{O}$ ato de escrever nos permite apreender uma realidade que até o momento se apresentava para nós de forma incompleta, velada, fugidia ou caótica. Muitas coisas as compreendemos só quando as escrevemos"22 [isto é, quando as comunicamos].

A comunicação de suas aprendizagens, por parte do sujeito que aprende, apresenta-se assim como um componente básico do processo de cognição e não apenas como um produto subsidiário desse processo. A construção do conhecimento e sua comunicação não são, como costumamos imaginar, duas etapas sucessivas através das quais primeiro o sujeito se apropria dele e depois o enuncia. São, isso sim, o resultado de uma interação:

20. KAPLÚN, M. Del educando oyente al educando hablante (Do educando ouvinte ao educando falante). Dia-logos de la comunicación. Lima: FELAFACS, n. 37, 1993.

21. GUTIERREZ, F., PRIETO CASTILLO, D. La mediación pedagógica (A mediação pedagógica). San José de Costa Rica: R.N.T.C., 1991. SERRANO, J. H. Hacia una cultura comunicativa (Por uma cultura comunicativa). Comunicar. Andalucía (España), n. 8, 1997.

22. RIBEYRO, J. R. Prosas apátridas. Barcelona: Tusquets, 1975. 
alcança-se a organização e a clareza desse conhecimento ao convertê-lo em um produto comunicável e efetivamente comunicado. Mas para que o educando se sinta motivado e estimulado a empreender o esforço de intelecção que essa tarefa supõe, necessita destinatários, interlocutores reais: escrever sabendo que vai ser lido, preparar suas comunicações orais com a expectativa de que será ouvido.

Educar-se é envolver-se em um processo de múltiplos fluxos comunicativos. O sistema será tanto mais educativo quanto mais rica for a trama de interações comunicacionais que saiba abrir e pôr à disposição dos educandos ${ }^{23}$. Uma Comunicação Educativa concebida a partir dessa matriz pedagógica teria como uma de suas funções capitais a provisão de estratégias, meios e métodos destinados a promover o desenvolvimento da competência comunicativa dos sujeitos educandos. Esse desenvolvimento supõe a geração de vias horizontais de interlocução e intercomunicação.

\section{MEIOS DE COMUNICAÇÃO E INFORMÁTICA}

Tenho a esperança de que, ainda que me servindo da simplificação imposta pela brevidade, não se tenha visto erroneamente no que aqui expus uma desqualificação em bloco da educação a distância, do emprego dos meios no ensino e da introdução no sistema educativo das modernas tecnologias informáticas.

A matriz individualizada e o paradigma informacional - eles sim, objetos de nossas observações críticas - não são realidades exclusivas do território da educação a distância. O ensino presencial - e temos nos preocupado em deixar claro - acha-se hoje permeado por eles em medida não muito menor. Por outro lado, é bom recordar que o modelo de ensino a distância de cunho individualizado é hoje certamente o hegemônico, mas de modo algum o único possível. Existem modalidades alternativas, de estrutura grupal e metodologia interacionista, as quais vêm deixando de ser tão-só propostas teóricas e estão sendo implementadas com êxito na América Latina, assim como em outras regiões do mundo ${ }^{24}$.

No que diz respeito ao emprego de meios na educação, bem-vindos sejam, desde que sejam aplicados crítica e criativamente, a serviço de um projeto pedagógico, ultrapassando a mera racionalidade tecnológica; como meios de comunicação e não de simples transmissão; como promotores do diálogo e da participação; para gerar e potenciar novos emissores mais que para continuar fazendo crescer a multidão de receptores passivos. Enfim, não meios que falam e sim meios para falar ${ }^{25}$.

Não foi nossa intenção negar a contribuição dos suportes informáticos nem desconhecer o papel imprescindível da informática nos processos de aprendizagem. Uma vez mais, a questão se fundamenta na estratégia comunicacional que preside seu uso. É necessário advertir que, em sua antecipação da "aula virtual", o texto que tomamos como expoente expressivo da tendência dominante, ao enumerar os múltiplos recursos informáticos postos à disposição do educando, não menciona as redes telemáticas, que possibilitariam a cada estudante,

23. KAPLÚN, M. A la educación por la comunicación (À edıcação para a comunicação). Santiago de Chile: UNESCOOREALC, 1992.

24. KAPLÚN, M. Repensar la educación a distancia desde la comunicación (Repensar a educação a partir da comuṇicação). Dia-logos de la comunicación. Lima: FELAFACS, n. 23, jun. 1992.

25. BELTRAN, L. R. Adios a Aristóteles. Comunicação horizontal (Adeus a Aristóteles. Comunicação horizontal). Comunicação \& Sociedade. São Paulo: Instituto Metodista de Ensino Superior, n. 6, 1980. KAPLÚN, M. Comunicación entre grupos (Comunicação entre grupos). Buenos Aires: Humanitas, 1990. 
ainda que na reclusão de sua sala de aula virtual, comunicar-se com outros e enriquecer-se reciprocamente na construção comum do conhecimento. Isso porque, quando se vê a educação a partir da perspectiva unidirecional para a qual o paradigma informacional colabora, tende-se quase inconscientemente a não atribuir valor à expressão dos educandos e a seus intercâmbios.

Felizmente, essas redes telemáticas já estão unindo e intercomunicando milhares de grupos de escolares e de estudantes do ensino secundário do mundo inteiro, abrindo-lhes canais de auto-expressão e interlocução, alargando seus horizontes e levando-os a ser mais participantes e mais solidários ${ }^{26}$. Pode-se esperar muito da evolução destas redes, inscritas, como estão, em um claro projeto pedagógico de afirmação dos valores humanos, organizadas para a comunicação entre grupos mais que entre indivíduos isolados e, portanto, como um alargamento da

Resumo: A maior parte dos sistemas educativos atuais - particularmente os de ensino a distância - privilegia uma matriz de ensino individualizada, dirigida a educandos isolados, e inibidora de sua auto-expressão. 0 presente trabalho analisa os efeitos pedagógicos e sociais desta modalidade e suas conseqüências para a futura configuração da comunicação educativa. Ressalta a importância do diálogo, próprio da educação presencial para o exercício da comunicação na formação de cidadãos livres e autônomos, comparando-o com a educação que se utiliza predominantemente da tecnologia, visando apenas à transmissão de informação, a qual pode acabar tornando o educando um ser autômato. Nesse contexto, o autor analisa a educação a distância.

Palavras-chave: educação a distância, Pedagogia, ensino presencial, uso das tecnologias comunicação cara-a-cara e não como sua substituição virtual.

Como se fosse conclusão: o que definirá em boa medida a concepção de Comunicação Educativa pela qual se opte nos próximos anos, será o valor que esta atribua à formação da competência comunicativa dos educandos.

Embora tenhamos nos centrado aqui na vertente cognitiva da educação, não é menos válido apontar que, quando se aspira a uma sociedade global humanizante, não avassalada pelo mercado, pela competitividade e pela homogeneização cultural e sim edificada sobre o diálogo, a cooperação solidária e a reafirmação das identidades culturais, o desenvolvimento da competência comunicativa dos sujeitos atuantes aparece como um fator altamente necessário, e em torno do qual gravitam os outros aspectos; como acontece, aliás, com a participação política e social.

Abstract: Most of the current educational systems - especially those involved in distance learning - privilege an individualized teaching matrix, directed towards isolated students. Such systems inhibit the students' self-expression. This article analyzes the pedagogical and social effects this modality has and its consequences for the future configuration of educational communication. It emphasizes the importance of the dialogue that is unique to presence education, in order to carry out communication aiming at forming free and autonomous citizens. It is compared to the education system that uses technology, predominantly, and has the objective of simply transmitting information, something that may end up turning the student into an automated being. In this context, the author analyzes distance learning.

Key words: distance learning, Pedagogy, presence teaching, use of the technologies

26. REYES, D. Estrellas solitarias en el barrio grupal (Estrelas solitárias em um arrabalde grupal). Buenos Aires: Doc. Policopiado, 1996. 